\title{
Photo Acoustic Energy Applications for the Detection of Human Arterial Blockages via Multiple Skin/Bone Layers, a Non-Invasive Approach
}

\author{
Monika Kakani ${ }^{1}$, Neeraj Rathi' ${ }^{1}$, Ahdy Helmy ${ }^{2}$, Ashok Kumar Thella', M. D. James Rizkalla ${ }^{3}$, \\ Paul Salama1, Maher E. Rizkalla ${ }^{1,4,5}$
}

${ }^{1}$ Department of Electrical and Computer Engineering, Indiana University Purdue University Indianapolis (IUPUI), Indianapolis, USA

${ }^{2}$ VA Hospital, Indiana University School of Medicine, Indianapolis, USA

${ }^{3}$ Baylor University Medical Center (BUMC), Dallas, USA

${ }^{4}$ Integrated Nanosystems Development Institute, IUPUI, Indianapolis, USA

${ }^{5}$ Richard G. Lugar Center for Renewable Energy, IUPUI, Indianapolis, USA

Email:mrizkall@iupui.edu

How to cite this paper: Kakani, M., Rathi, N., Helmy, A., Thella, A.K., Rizkalla, M.D.J., Salama, P. and Rizkalla, M.E. (2017) Photo Acoustic Energy Applications for the Detection of Human Arterial Blockages via Multiple Skin/Bone Layers, a Non-Invasive Approach. World Journal of Cardiovascular Diseases, 7, 251-270.

https://doi.org/10.4236/wjcd.2017.78024

Received: July 22, 2017

Accepted: August 25, 2017

Published: August 28, 2017

Copyright $\odot 2017$ by authors and Scientific Research Publishing Inc. This work is licensed under the Creative Commons Attribution International License (CC BY 4.0).

http://creativecommons.org/licenses/by/4.0/

\begin{abstract}
The impact of arterial narrowing/blocking caused by plaque buildup in arteries leads to many life-threatening consequences. This is recognized as a cause in heart attacks and peripheral vascular disease. Diagnosing the illness is only feasible after symptoms have presented to the patient. Currently, the standard for visualizing coronary arteries is through angiography, which may have complications, and impact on the healthcare system. Furthermore, cardiac catheterization may also places high health risks, given its overall invasiveness. Cardiac arrhythmias, infection, and contrast dye nephrotoxicity are recognized complications within this process. Therefore, a noninvasive approach may have potentials to reduce patient complications, finances surrounding healthcare, and more efficient patient care through earlier screening and diagnosing. This research addresses a new approach using photoacoustic (PA) imaging. The transmission properties of atherosclerosis within walls of arteries, can be exploited using photo acoustics, to better visualize and characterize the degree and severity of atherosclerosis. The delivered energy is absorbed by components of the vascular tissue converted into heat, leading to transient thermos elastic expansion, which creates an acoustic emission. The thermal response was analyzed for its fall and recovery times that are attributed to the artery fat type. The control parameters, including the frequency, penetration depth, energy levels, and tissue layer sizes, for multilayered structures were considered. The struc-
\end{abstract}


tures investigated were fatty infiltrate within the artery, blood, bones, and skin, within frequency range from $1 \mathrm{MHz}$ to $3 \mathrm{MHz}$, and typical tissue sizes in the milli to centimeter range. As high as $14 \mathrm{MPas}$ in the acoustic pressure at $1 \mathrm{MHz}$, resulted in temperature difference of up to $3.4 \mathrm{~K}$. When the operating frequency was altered to $2 \mathrm{MHz}$, the temperature changed to $23 \mathrm{~K}$. Furthermore, when the frequency was changed to $3 \mathrm{MHz}$, the temperature moved to $43 \mathrm{~K}$. The changes in temperatures were for nearly 1 second duration. The results obtained in this study suggest that there is high potential for practical models using flexible substrate with infra-red sensors and acoustic devices.

\section{Keywords}

Acoustic, Thermal, Cardiovascular, Diagnosis, MEMS/NEMS, COMSOL, Multilayers, Non-Invasive

\section{Introduction}

Coronary artery disease, which affects a massive population of the United States, is directly correlated to the degree of atherosclerosis within the blood vessel. Risk factors such as unfavorable genetics, diabetes, and hyperlipidemia play a strong correlative role in the development of atherosclerosis and cardiovascular disease. On a molecular level, cholesterol and lipoproteins play a vital role in the development of atherosclerotic plaques. More specifically, lipoproteins, which are biochemical compounds used in the transfer of cholesterol within the body, have been studied and recognized as playing an instrumental role in the development of atherosclerosis. Therefore, with increased cholesterol levels, the levels of lowdensity-lipoproteins (LDL) increase concomitantly, and, ultimately, the risk for vascular disease secondary to atherosclerosis. While cholesterol and LDL levels can be frequently checked on routine labs, it is difficult to assess the degree of atherosclerosis within a patient at any given time. Physical exam findings usually will not present until the patient's cardiovascular status has progressed to present symptomatically. Currently, there lacks a non-invasive or monetarily efficient method of screening patients for atherosclerosis and cardiovascular disease without complex and invasive medical imaging

From a medical imaging standpoint, one way to categorize procedures is: invasive vs non-invasive. Generally speaking, an invasive technique involves a surgical procedure, the use of "entering" within the human body through an anatomical opening, or delivering an external substance internally to a patient. Invasive techniques are generally more expensive, have a higher complication rate, and more consequences for the patient. With a greater push towards "valuebased" healthcare and outcomes, there is a definite pushback against invasive procedures within all fields of medicine. In contrast, non-Invasive imaging is a technique used to image the internal parts of human body without involving any surgical process. The limitations, however, is that non-invasive imaging may 
have worse quality, exposure to radiation, or lead to difficulty making critical diagnoses. Some examples of non-invasive imaging are, but not limited to: Magnetic resonance imaging (MRI), Computed tomography (CT), Ultrasound or medical ultrasonography, Thermography, Positron emission tomography (PET), and Photo acoustic imaging. As stated, each of these non-invasive imaging modalities presents its own limitations, costs, and complications. For instance, in the MRI scanning, the magnetic field generated by MRI scanner attracts any metal objects and may cause cardiac pacemakers, defibrillation devices, and cochlear implants to malfunction. Limitations to CT scanning include artifact, high-dose radiation exposure, and potential renal complications due to contrast dye. Finally, the limitations of ultrasound include poorer image quality and more extreme emphasis and success rates on the user's technical imaging skills-requiring a higher skilled operator.

Regardless of limitations, biomedical applications using photoacoustic (PA) imaging has come a long way in the last decade [1] [2] [3] [4] [5]. The spatial resolution and the maximum imaging depth of the PA images can be manipulated with the ultrasonic bandwidth [6]. Spatial resolution of $1 \mathrm{~mm}$ can be produced by the signals with a bandwidth of $1 \mathrm{MHz}$, while increasing the bandwidth to $10 \mathrm{MHz}$ produces a spatial resolution of $0.1 \mathrm{~mm}$, aiding in ultrasonic penetration. While basic ultrasound has some issues with quality, when optical and acoustic imaging is combined together, the quality of imaging seen increases dramatically. The higher contrast photos are generated, without any radiation to the patient. An optical laser pulse is generated onto the tissue's surface, which is scattered and absorbed by the tissue itself. The energy is then converted into both sound waves and heat, which are monitored, in real-time, and collected by a transducer. The combination of signals is recollected and used to generate a high resolution image, with minimal time delay, and minimal overall complications. Figure 1 indicates the relation between the acoustic and thermal energy generated from the photoacoustic source applied to the human tissue. As shown in the diagram, the process starts by applying a laser pulse. The pulse energy is then absorbed by the human tissue, resulting in rising temperature, leading to thermal expansion and generation of acoustic waves. This wave may be detected via ultrasound sensors, and an image may be formed.

\section{The Mathematical Model}

Under the assumption that the source of energy was initially acoustic pressure, the energy conversion to bioheat occurs inside the various tissue layers. Therefore, the solutions of dynamic and special pressure and temperature throughout

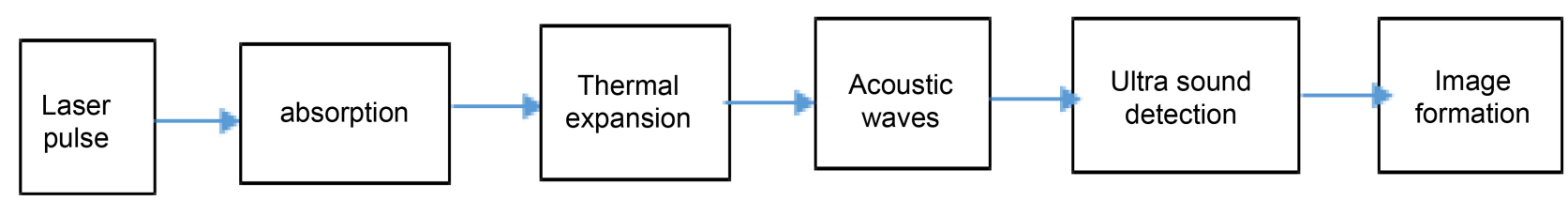

Figure 1. Block diagram for photoacoustic imaging. 
the multiple tissue layers are governed by the acoustic wave equation and the Bio heat equation.

\subsection{The Acoustic Wave Equations}

The acoustic wave equations used in this simulations are given as:

$$
\nabla \cdot\left(-\frac{1}{\rho_{c}}\left(\nabla p_{t}-q_{d}\right)\right)-\frac{k_{e q}^{2} p_{t}}{\rho_{c}}=Q_{m}
$$

where $p_{t}=p+p_{b}$, and $p$ is the acoustic pressure, $p_{b}$ is the biological thermal pressure, and $k_{e q}$ the wave number is given in Equation (2) below.

$$
\begin{aligned}
& k_{e q}^{2}=\left(\frac{\omega}{c_{c}}\right)^{2}-k_{m}^{2}, k_{m}=\frac{m}{r} \\
& c_{c}=\frac{\omega}{k}, ? k=\frac{\omega}{c}-i \alpha, \rho_{c}=\frac{\rho c^{2}}{c_{c}^{2}}
\end{aligned}
$$

where $\mathrm{m}$ is the mass density, $r$ is the location in space, $\mathrm{w}$ is the radian frequency, $Q_{m}$ is the metabolic heat source, $\alpha$ is the absorption co-efficient, and $c$ is the speed of the sound. The boundary conditions by the normal components of the amplitude at the boundary wall, and at normal displacement $d_{n}$ is given in Equation (4) below.

$$
\begin{gathered}
-n \cdot\left(-\frac{1}{\rho_{c}\left(\nabla p_{t}-q_{d}\right)}\right)=0 \\
-n \cdot\left(-\frac{1}{\rho_{c}\left(\nabla p_{t}-q_{d}\right)}\right)=(i \omega)^{2} d_{n}
\end{gathered}
$$

where $n$ is the unit normal vector normal to the interface boundary, and $\rho$ is the material density. An initial pressure of $1 \mathrm{MPa}$ applied to the skin layer was applied. Figure 2 shows the pressure pulse assumed in the simulation.

\subsection{Bio Heat Equations}

The Bio heat equation used in the study is given below in Equations (5) to (7):

$$
\begin{gathered}
\rho c_{p} \nabla T+\nabla \cdot q=Q+Q_{b i o} \\
Q_{b i o}=\rho_{b} C_{p, b} \omega_{b}\left(T_{b}-T\right)+Q_{m e t} \\
q=-k \nabla T
\end{gathered}
$$

where $T$ is the temperature, $\rho$ is the density, $C_{p}$ is the specific heat, $k$ is the thermal conductivity, $\rho_{b}$ is the density of blood, $C_{b}$ is the specific heat of blood, $w_{b}$ is the blood perfusion rate, $T_{b}$ is the temperature of the blood, $Q$ is the heat, and $Q_{m e t}$ is the metabolic heat source. The energy source is located at the site of the artery, then released into the multiple layers, generating a temperature pattern that may be recognized afterwards. The variation in this pattern will help to elucidate the degree and severity of atherosclerosis within a blood vessel. The acoustic energy may be placed via an external acoustic source that is designed to 


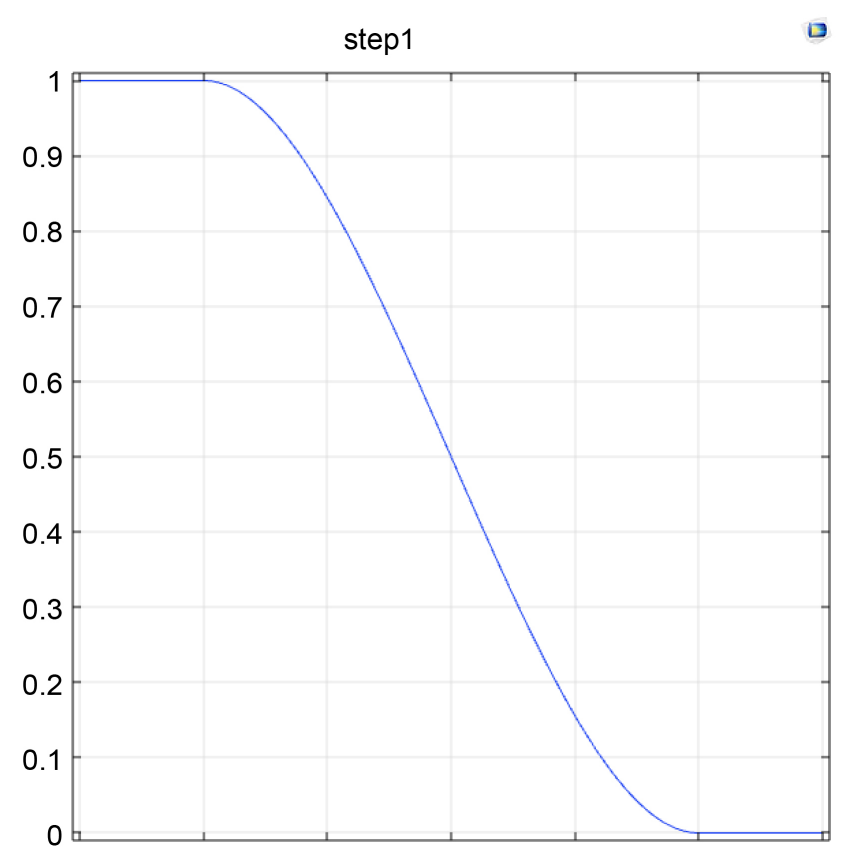

0

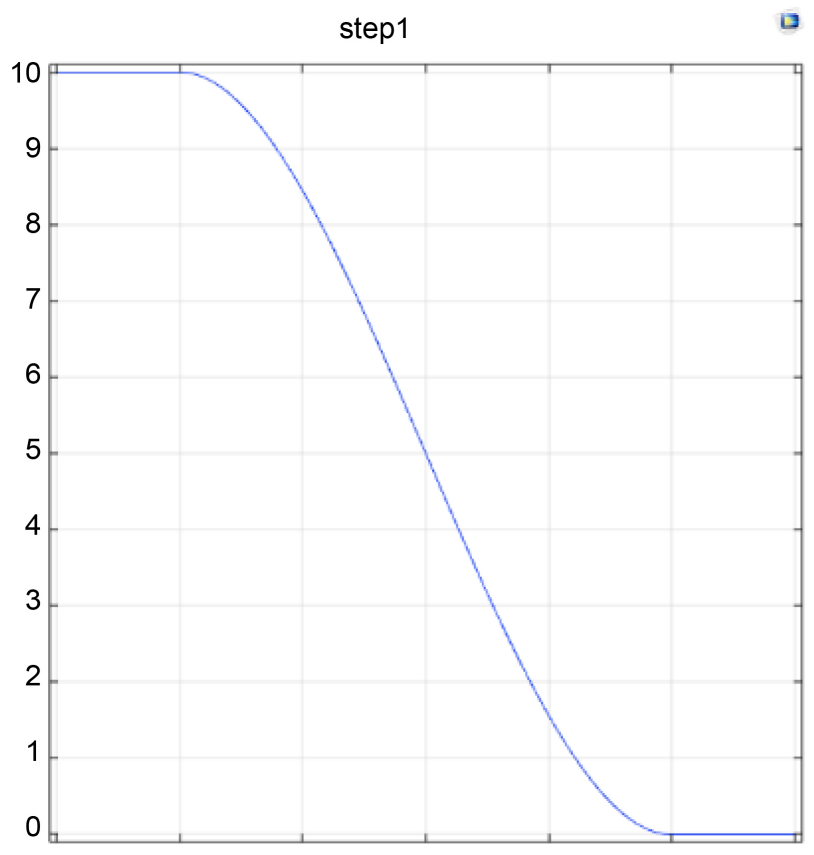

Figure 2. Pressure pulses assumed for the simulation, given at $1 \mathrm{MPa} \cdot \mathrm{s}$ and $10 \mathrm{MPa} \cdot \mathrm{s}$. The pressure response is given versus time in second.

deliver the energy from a distance. Therefore, the thermal and acoustic energy are localized at the artery site, propagating via the blood, bone, and skin. Figure 3 shows the layer set up for the simulation model. The fist layer from the bottom represents the skin, followed by the bone layer, then the blood. The tiny circular part in the middle of the model represents the artery fat tissue. In this model, the energy absorbed by the fat tissue will be released into the other multiple layers. The response time may be utilized for the detection of the artery fat type. Figure 4 and Figure 5 show the mesh distributions with $12 \mathrm{~mm}$ and $6 \mathrm{~mm}$ meshes respectively given at $40 \mathrm{~cm}^{2}$ blood area. The system uses two types of meshes: a finer mesh for the corners near the fat region where the source energy is, and slightly thicker mesh for the blood region. The thinner mesh was chosen in order to cover the small size fat where the energy was localized.

\section{Results and Discussions}

The model has been simulated for three different frequencies $1 \mathrm{MHz}, 2 \mathrm{MHz}$ and $3 \mathrm{MHz}$. Apart from the point of focus, three different out of focus points have been considered and the change in temperature rise has been estimated.

The acoustic pressure energy sourced at the atherosclerotic region results in thermal energy conversion that propagates into the fat, blood, and skin regions. Furthermore, the reflected acoustic wave will also propagate via the same media. The thermal propagation patterns may be analyzed to distinguish the degree of atherosclerosis assumed in the simulation. The following simulation results show the temperature distribution at the source (fat region; designated in the red curve), while the temperature distributions are determined at the various locations 


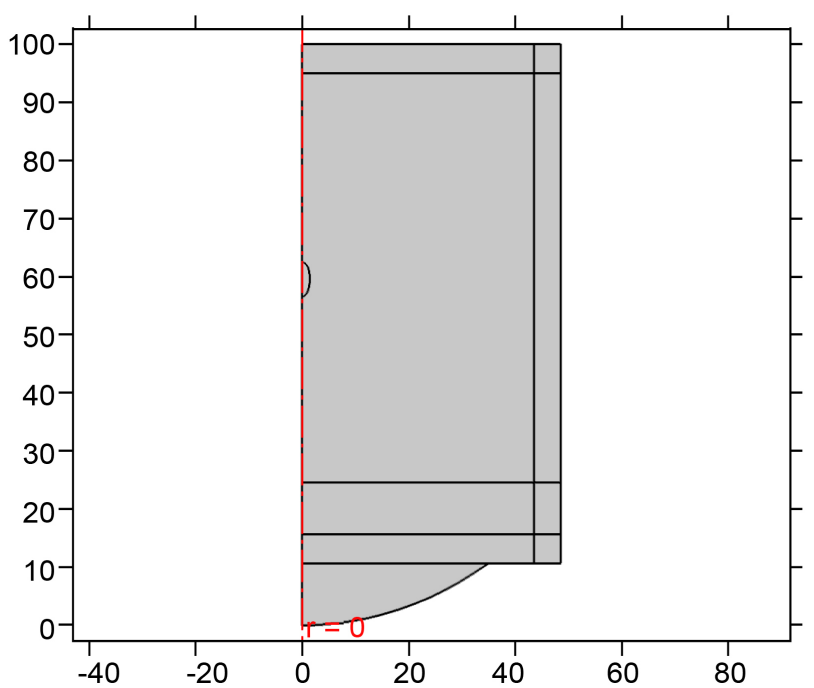

Figure 3. Layer set up for the simulation model.

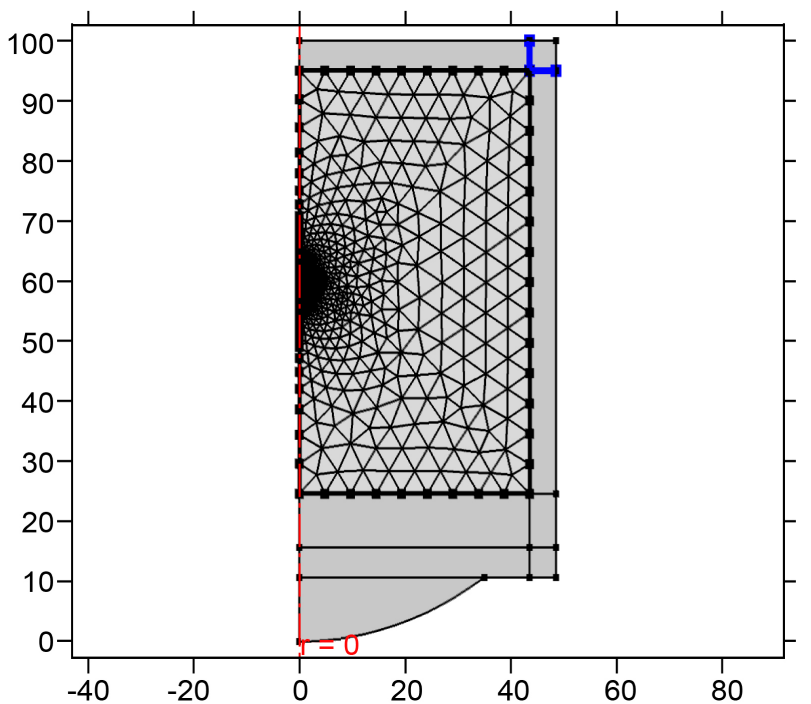

Figure 4. Mesh distribution within the blood material and fat.

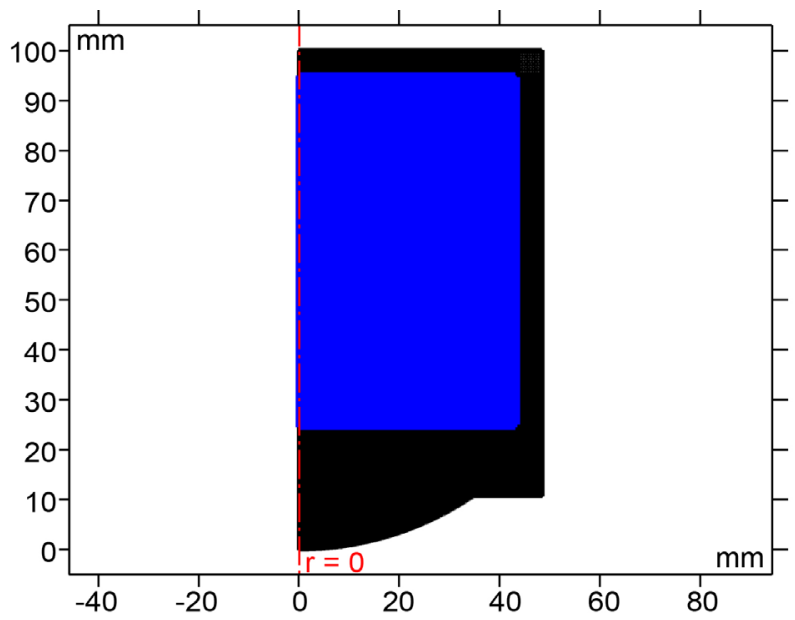

Figure 5. Mesh distribution within skin and bone. 
from the source: $50 \mathrm{~mm}, 57 \mathrm{~mm}$, and $70 \mathrm{~mm}$ (these are designated in the blue curves in the curve results). The source of energy (the fat) is located at $59.6 \mathrm{~mm}$ from the origin (see Figure 3 and Figure 4). As indicated in the governing Equations (7), (8), and (9) given below, the acoustic pressure, and accordingly, the thermal energy is function of the frequency and magnitude of the acoustic pressure. In our simulation, we considered three different frequencies: $1 \mathrm{MHz}, 2$ $\mathrm{MHz}$, and $3 \mathrm{MHz}$. The initial pressure, $p_{0}$ source, was also altered to increase the energy level, following Equations (8) and (9) below.

$$
\begin{gathered}
I=\frac{1}{2} \rho v \omega^{2} x^{2} \\
I=P V
\end{gathered}
$$

where $I$ is the intensity of the energy, $\rho$ is the density of the material, $V$ is the velocity, $\omega$ is the angular frequency, $P$ is the pressure and $V$ is the velocity. Comparing Equations (8) and (9), we get a relation between the angular frequency and the pressure showing that $p \alpha \omega^{2}$.

\subsection{Temperature Profile}

The study considers the temperature distribution from the three energy sources with $1 \mathrm{MHz}, 2 \mathrm{MHz}$, and $3 \mathrm{MHz}$, for both the fat and non-fat materials.

\subsection{1. $1 \mathrm{MHz}$ One Joule Energy Source}

1) Fat source

In this case, the energy source is applied to LDL fat source, and the simulation was determined at three difference locations to data analysis. The simulations were determined at $50 \mathrm{~mm}(9.6 \mathrm{~mm}$ below the fat center area), $57 \mathrm{~mm}(1.5 \mathrm{~mm}$ from the center fat area), and $70 \mathrm{~mm}(10.4 \mathrm{~mm}$ above the fat center region) are as follows. The temperature at the point of focus remains constant but the temperature drops as we go out of focus. At focus, the temperature absorbed was 3.4 $\mathrm{K}$ above the body temperature $(293.9 \mathrm{~K})$, while off focus the temperature at 57 $\mathrm{mm}$ was estimated to be $2 \mathrm{~K}$, and was dropped to $0.4 \mathrm{~K}$, and $0.45 \mathrm{~K}$ at $50 \mathrm{~mm}$ and $70 \mathrm{~mm}$ respectively. A temperature change of $\Delta T=3.4-2=1.4 \mathrm{~K}$ occurred at $57 \mathrm{~mm}$, a change of $\Delta T=3.4-0.4=3 \mathrm{~K}$ at $50 \mathrm{~mm}$, and a change of $\Delta T=3.4-$ $0.45=2.95 \mathrm{~K}$ at $70 \mathrm{~mm}$. It is clear that the temperate dropped to $0.5 \mathrm{~K}$ near the bone area. Figure 6 shows the temperature profile for the fat material at $50 \mathrm{~mm}$, $57 \mathrm{~mm}$, and $70 \mathrm{~mm}$ at $1 \mathrm{MHz}$.

2) Nonfat source

Similar simulation was done considering a non-fat material source, and the temperature distribution was determined at the three locations $50 \mathrm{~mm}, 57 \mathrm{~mm}$ and $70 \mathrm{~mm}$ for $1 \mathrm{MHz}$. Figure 7 shows the temperature profile for non-fat material at 50,57 , and $70 \mathrm{~mm}$ at $1 \mathrm{MHz}$.

The temperature at focus dropped when material used is nonfat. The temperature at focus was $2 \mathrm{~K}$ while it is 0.9 at $57 \mathrm{~mm}, 0.4$ at $70 \mathrm{~mm}$ and it is almost zero at $50 \mathrm{~mm}$. At focus the temperature was $2 \mathrm{~K}$, while off focus the temperature at $57 \mathrm{~mm}$ is $1 \mathrm{~K}$, and was dropped to $0.3 \mathrm{~K}$ and $0.4 \mathrm{~K}$ at $50 \mathrm{~mm}$ and $70 \mathrm{~mm}$. 

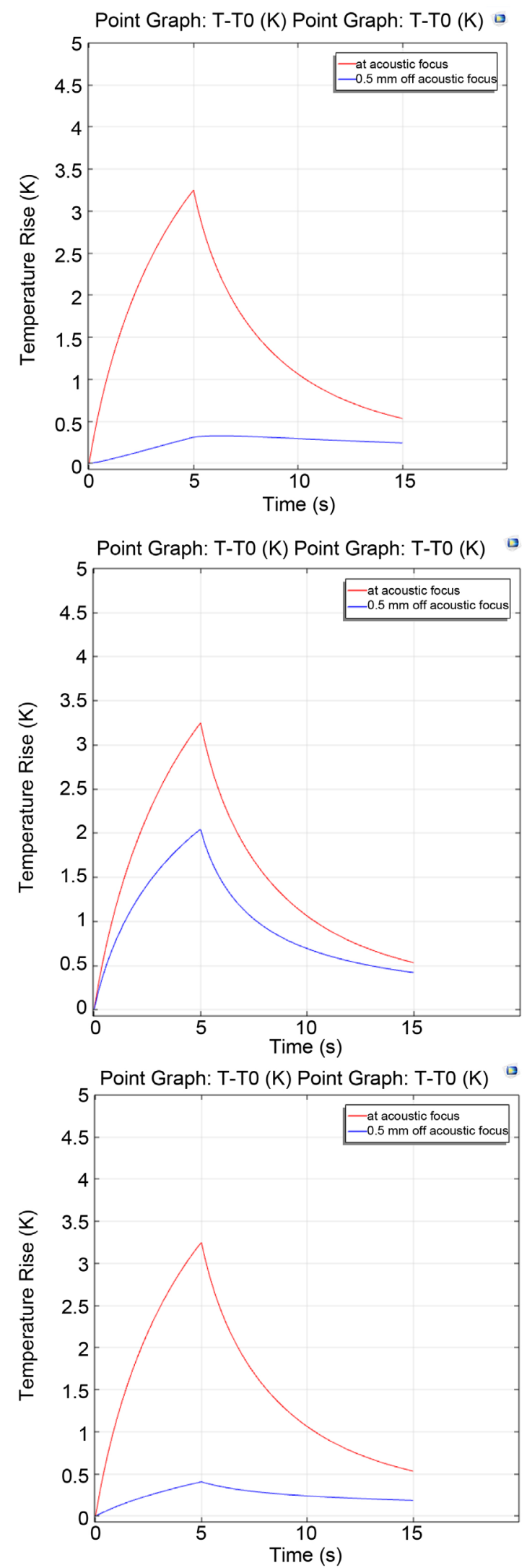

Figure 6. Temperature profile for fat at $50 \mathrm{~mm}, 57 \mathrm{~mm}$, $70 \mathrm{~mm}$ at $1 \mathrm{MHz}$. 

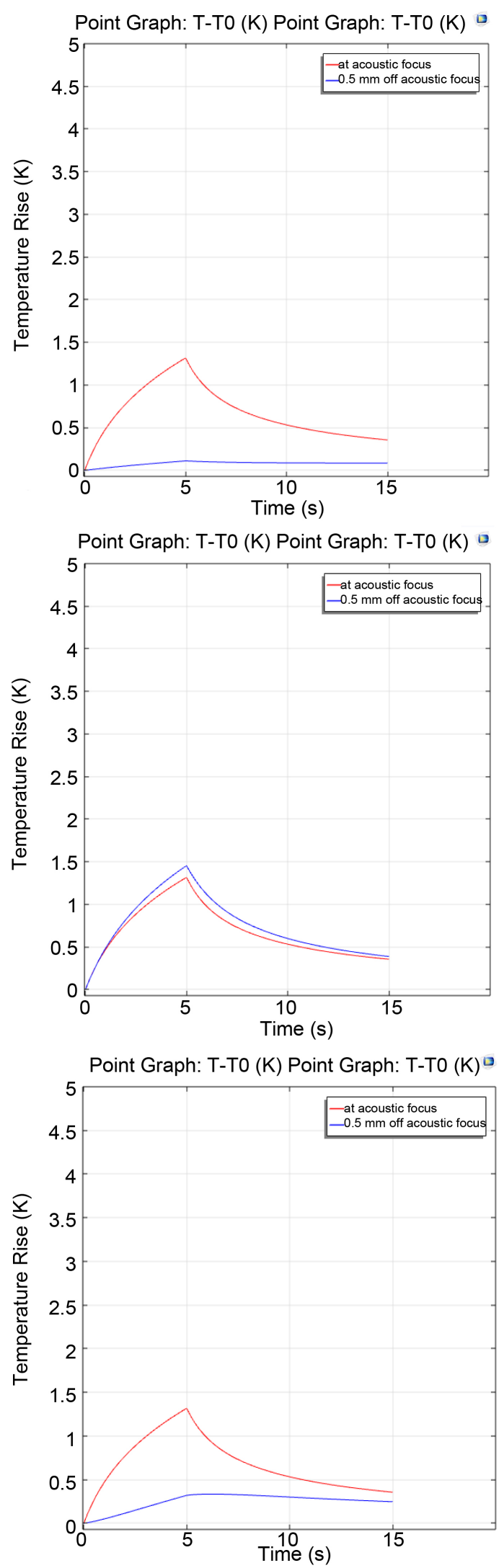

Figure 7. Temperature profile for non-fat material at $50 \mathrm{~mm}, 57 \mathrm{~mm}$, and $70 \mathrm{~mm}$ at $1 \mathrm{MHz}$. 
A temperature change of $\Delta T=1.4-1.3=0.1 \mathrm{~K}$ occurred at $57 \mathrm{~mm}$, and a change of $\Delta T=1.4-0.25=1.15 \mathrm{~K}$ at $50 \mathrm{~mm}$, and a change of $\Delta T=1.4-0.4=1$ $\mathrm{K}$ at $70 \mathrm{~mm}$.

\subsubsection{MHz One Joule Energy Source}

With the increase in frequency the temperature increases. The temperature at the point of focus rises to $27 \mathrm{~K}$. While the temperature off focus is less at $50 \mathrm{~mm}$ and $70 \mathrm{~mm}$ compared to the temperature at $57 \mathrm{~mm}$. The temperature for the nonfat decreases when compared to the temperature for fat. A temperature change of $\Delta T=23-12=11 \mathrm{~K}$ has been observed at $57 \mathrm{~mm}$ while a change in $\Delta T$ of $\Delta T=23-0=23 \mathrm{~K}$ at $50 \mathrm{~mm}$ and $22 \mathrm{~K} 70 \mathrm{~mm}$ has been noticed. Figure 8 shows the temperature profile for fat material at $50 \mathrm{~mm}, 57 \mathrm{~mm}$, and $70 \mathrm{~mm}$ at 2 $\mathrm{MHz}$ frequency.

For non-fat material the temperature at focus decreases to $9 \mathrm{~K}$ at focus while a change in temperature $\Delta T=9-7=2 \mathrm{~K}$ has been noticed at $57 \mathrm{~mm}$ while the change remains $9 \mathrm{~K}$ at $50 \mathrm{~mm}$ and $8 \mathrm{~K} 70 \mathrm{~mm}$. Figure 9 shows the temperature profile for non-fat material at $50 \mathrm{~mm}, 57 \mathrm{~mm}$, and $70 \mathrm{~mm}$ at $2 \mathrm{MHz}$.

\subsection{3. $3 \mathrm{MHz}$ One Joule Energy Source $3 \mathrm{MHz}$}

The simulation given here is based on the same energy but the frequency is increased to $3 \mathrm{MHz}$. The temperature at the point of focus increases to $43 \mathrm{~K}$ at the point of focus while a change in temperature of $\Delta T=43-25=18 \mathrm{~K}$ has been observed at $57 \mathrm{~mm}$, and a change remains $43 \mathrm{~K}$ at $50 \mathrm{~mm}$ and $42 \mathrm{~K}$ at $70 \mathrm{~mm}$. Figure 10 and Figure 11 give the temperature profile for the fat and non-fat materials respectively at $50 \mathrm{~mm}, 57 \mathrm{~mm}$ and $70 \mathrm{~mm}$.

In a similar pattern, the temperature at focus drops to $23 \mathrm{~K}$ for nonfat material. We also noticed a temperature change of $\Delta T=23-18=5 \mathrm{~K}$ at $57 \mathrm{~mm}$ and the change in temperature $\Delta T$ remains $23 \mathrm{~K}$ at $50 \mathrm{~mm}$ and $22 \mathrm{~K}$ at $70 \mathrm{~mm}$. Figure 12 gives the distributions at the bone materials for $1 \mathrm{MPa} \cdot \mathrm{s}$.

The temperature near the bones is zero hence an increase in the pressure pulse have been made to notice a significant temperature change at the bones. The simulations for $P_{0}=10 \mathrm{MPa} \cdot \mathrm{s}$ at $50 \mathrm{~mm}, 57 \mathrm{~mm}$ and $70 \mathrm{~mm}$ for the frequencies 1 $\mathrm{MHz}, 2 \mathrm{MHz}$ and $3 \mathrm{MHz}$ are shown respectively in Figures 13-15. The simulations at bones for when the pressure pulse has been raised to 10 in Figures 16.

\section{Conclusions and Future Work}

A proposed procedure for the practical model for the simulation results presented here may follow two approaches:

1) Considering a device that can shoot the energy from outside far enough to reach the arteries [7], then the energy source will be turned off in order to let the artery fat releases the energy via their natural thermal and acoustic fall time responses. These responses will be attributed to the type of fat within the artery.

2) The approach may consider applying an energy source from outside (by the skin tissue). The energy will propagate via the multiple layers until reaching the 

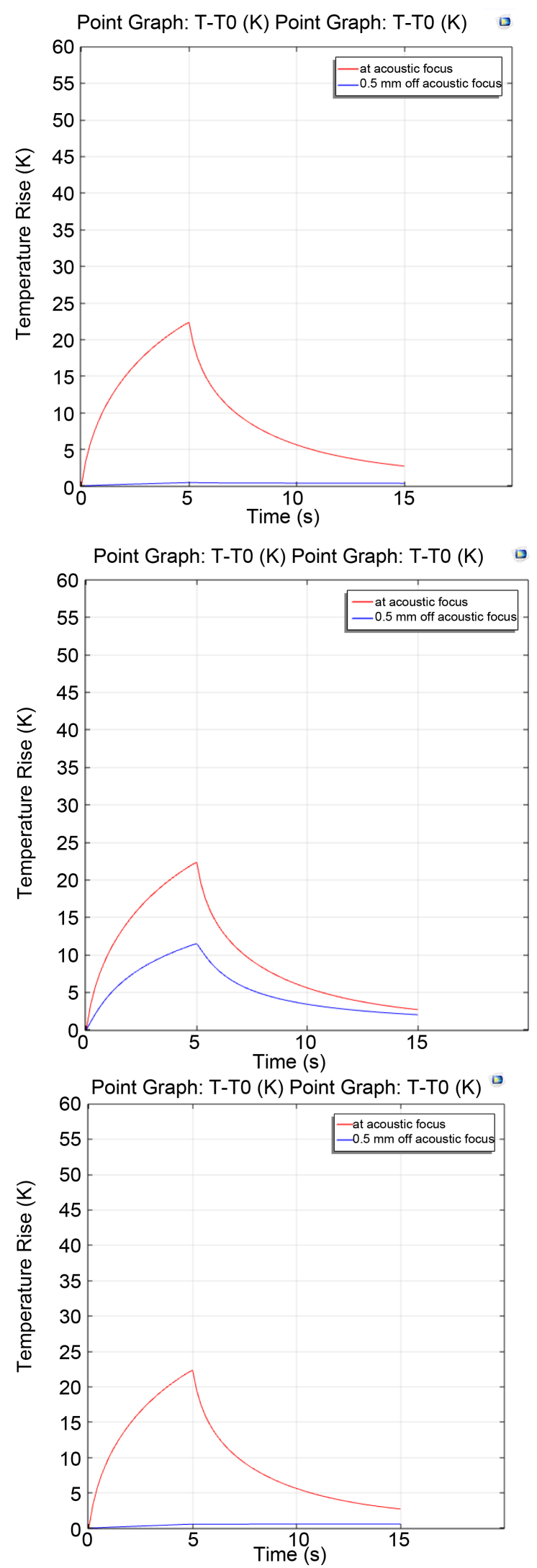

Figure 8. Temperature profile for fat at $50 \mathrm{~mm}, 57 \mathrm{~mm}$, $70 \mathrm{~mm}$ at $2 \mathrm{MHz}$. 

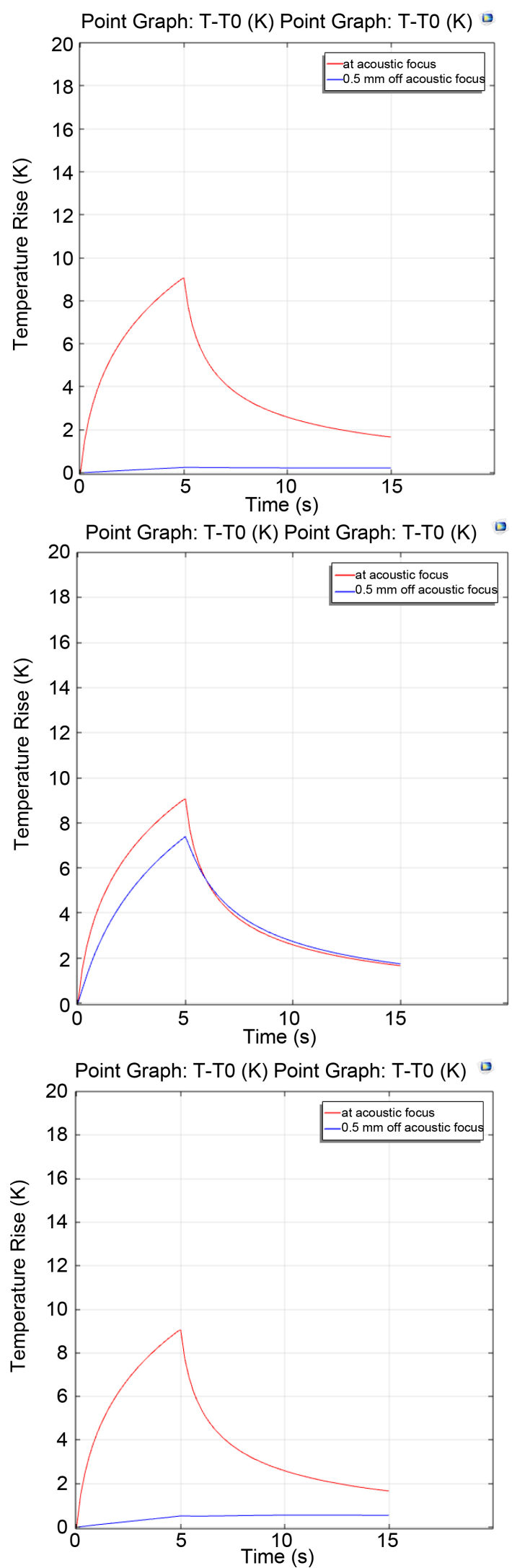

Figure 9. Temperature profile for non-fat material at $50 \mathrm{~mm}, 57 \mathrm{~mm}$, and $70 \mathrm{~mm}$ at $2 \mathrm{MHz}$. 

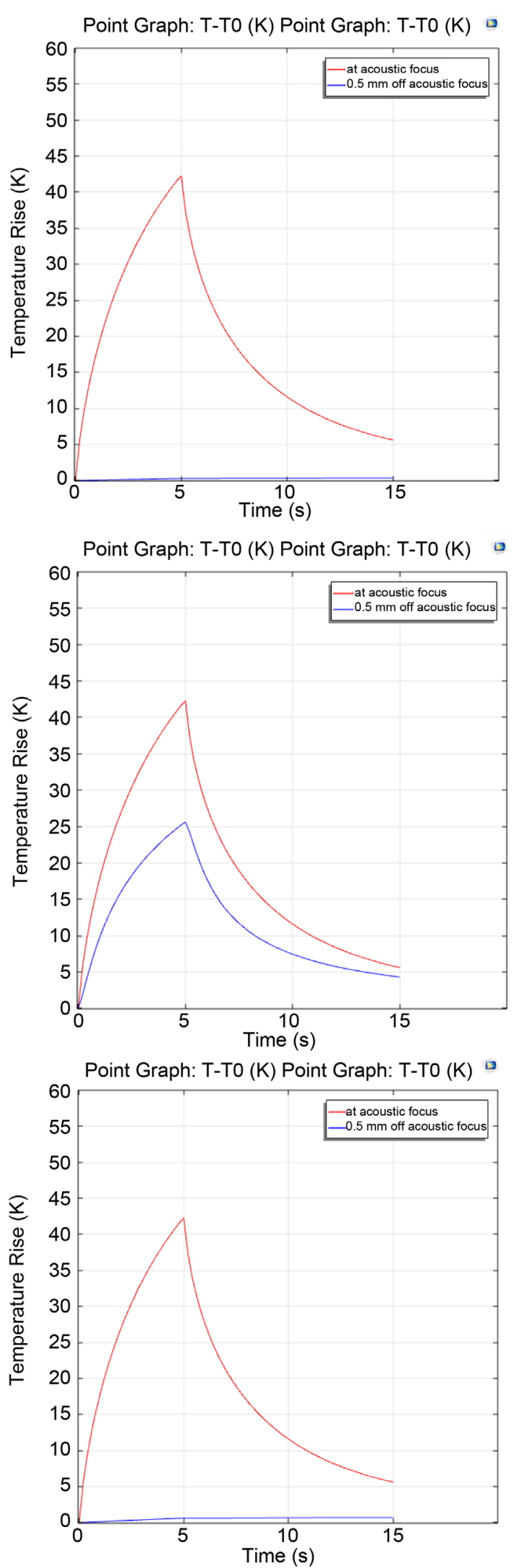

Figure 10. Temperature profile for fat at $50 \mathrm{~mm}, 57$ $\mathrm{mm}, 70 \mathrm{~mm}$ at $3 \mathrm{MHz}$. 

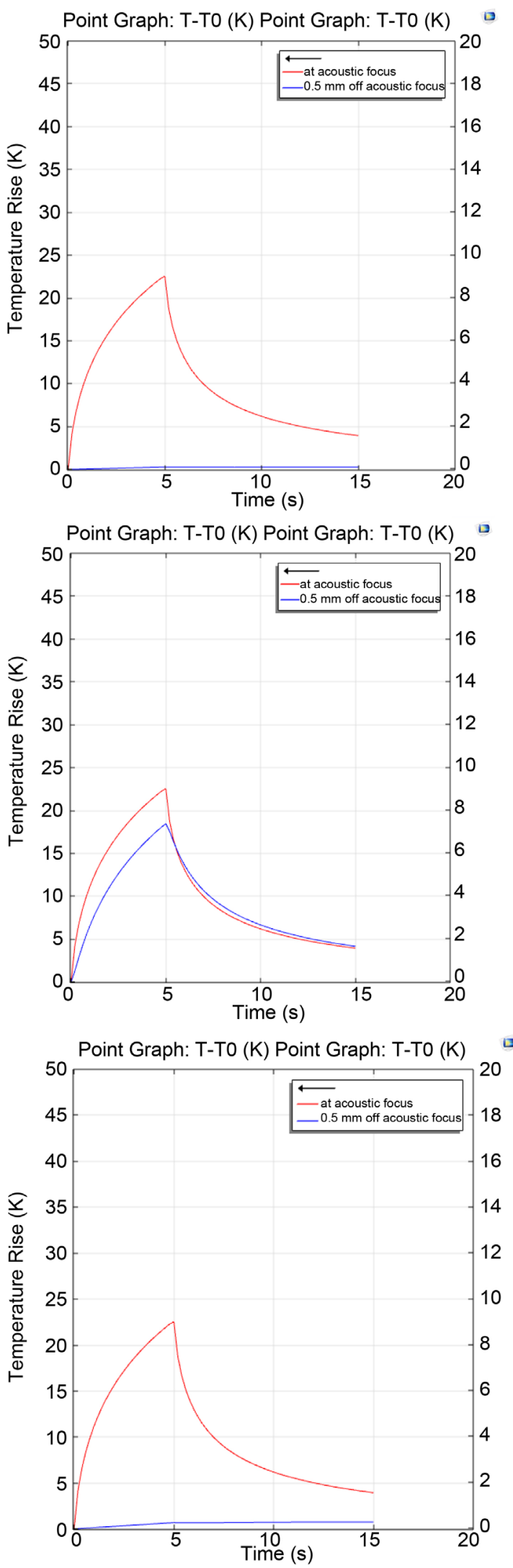

Figure 11. Temperature profile for nonfat at $50 \mathrm{~mm}, 57$ $\mathrm{mm}$, and $70 \mathrm{~mm}$ at $3 \mathrm{MHz}$. 

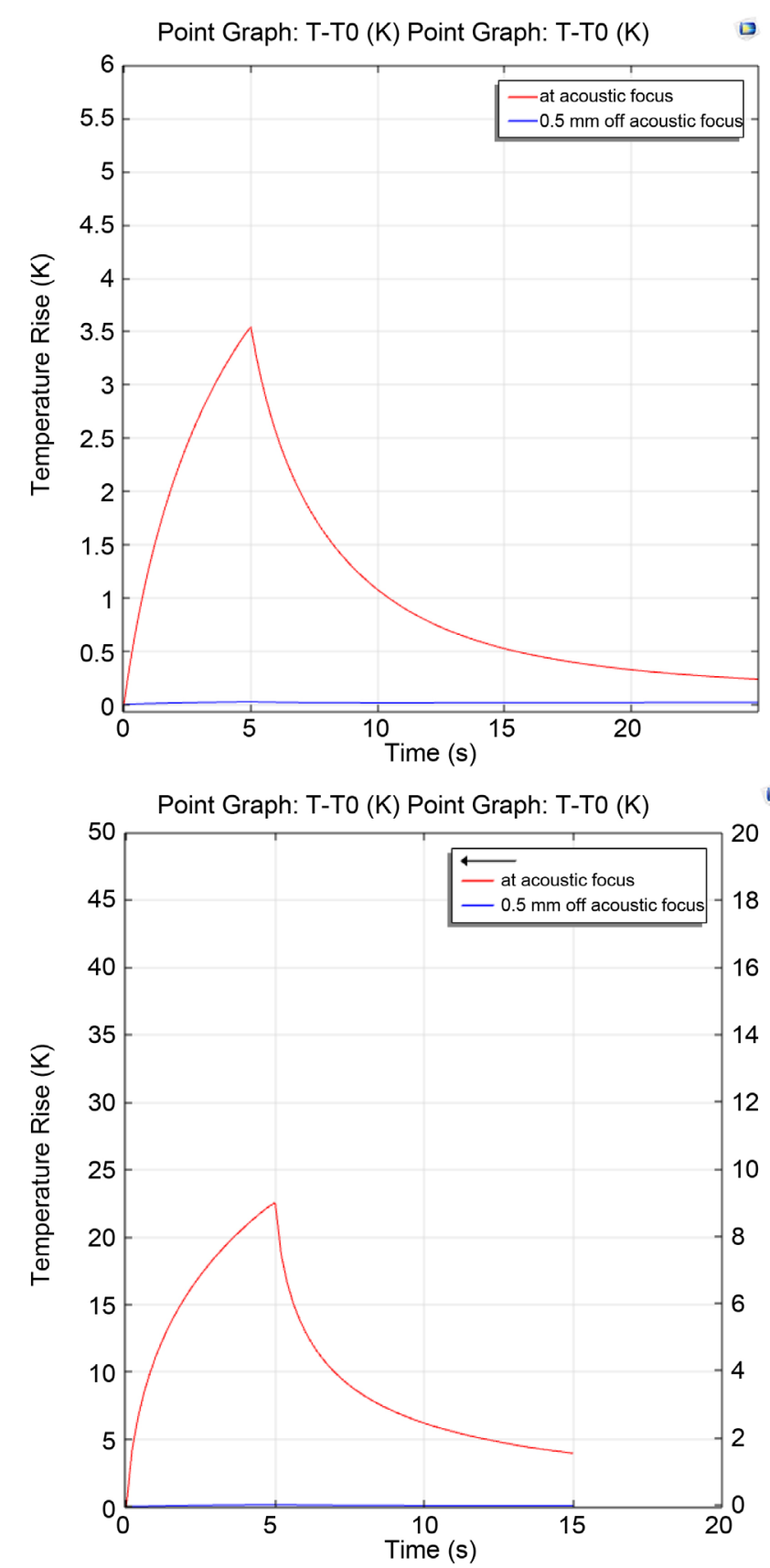

Figure 12. Temperature profile near bones for fat and non fat material at $3 \mathrm{MHz}$ for $p_{0}=1 \mathrm{MPa} \cdot \mathrm{s}$.

artery. The artery will preserve more of thermal energy and slowing releases the energy via its fall time response. The process here, considers applying energy pulses for a short period (one second for instance), then following the fall time response of the artery throughout the layers' boundaries. This approach is based on the distinguished fall time responses of the fat materials reported her, and the bone materials presented elsewhere [8]. The transducers that provide the thermal and acoustic responses are commonly known devices within the field of Micro electro mechanical systems (MEMS) and nano electro mechanical systems 

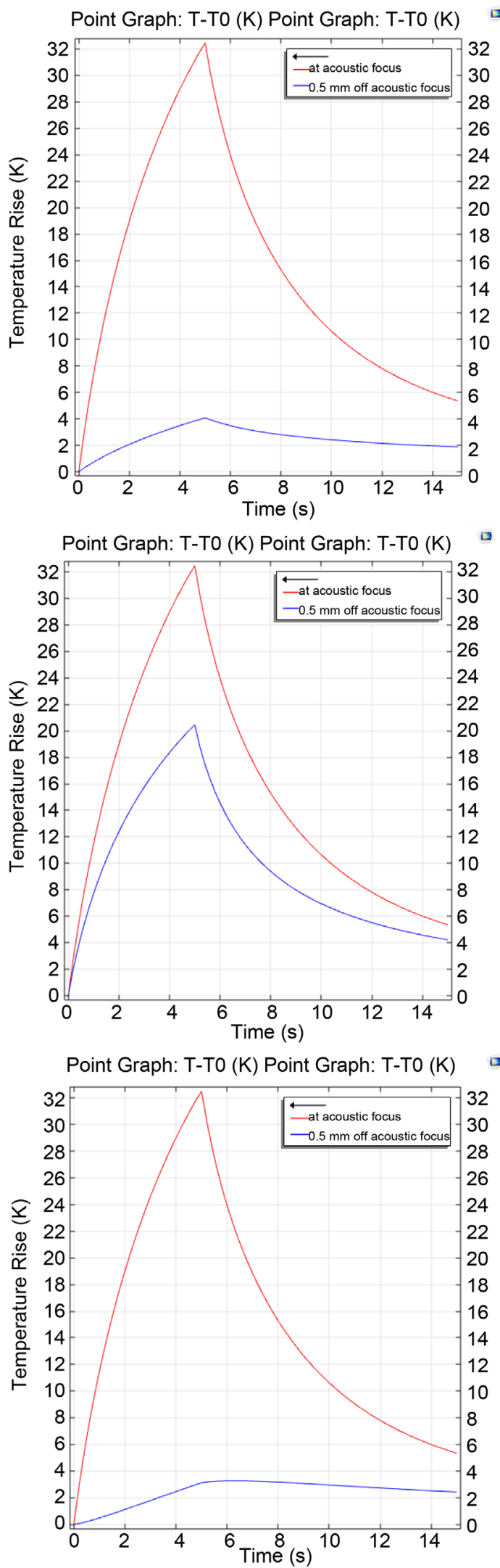

Figure 13. Temperature profile near fat at $50 \mathrm{~mm}, 57$ $\mathrm{mm}$, and $70 \mathrm{~mm} p_{0}=10 \mathrm{MPa} \cdot \mathrm{s}$ at $1 \mathrm{MHz}$. 

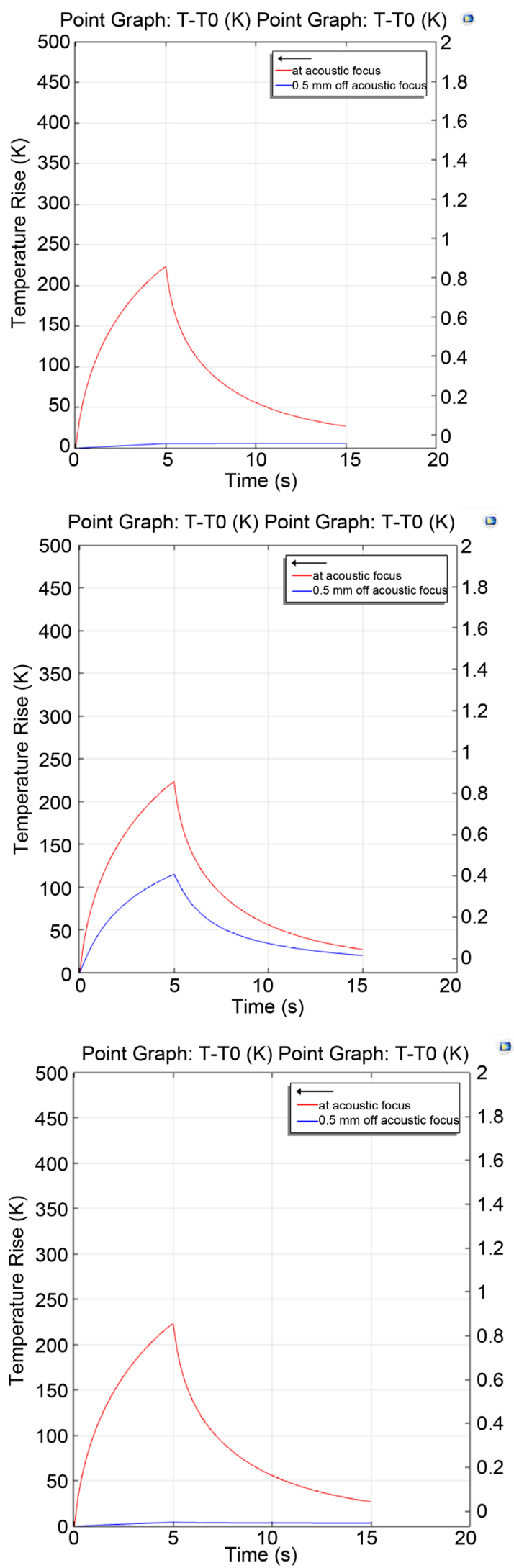

Figure 14. Temperature profile near fat at $50 \mathrm{~mm}, 57$ $\mathrm{mm}, 70 \mathrm{~mm} p_{0}=10 \mathrm{MPa} \cdot \mathrm{s}$ at $2 \mathrm{MHz}$. 

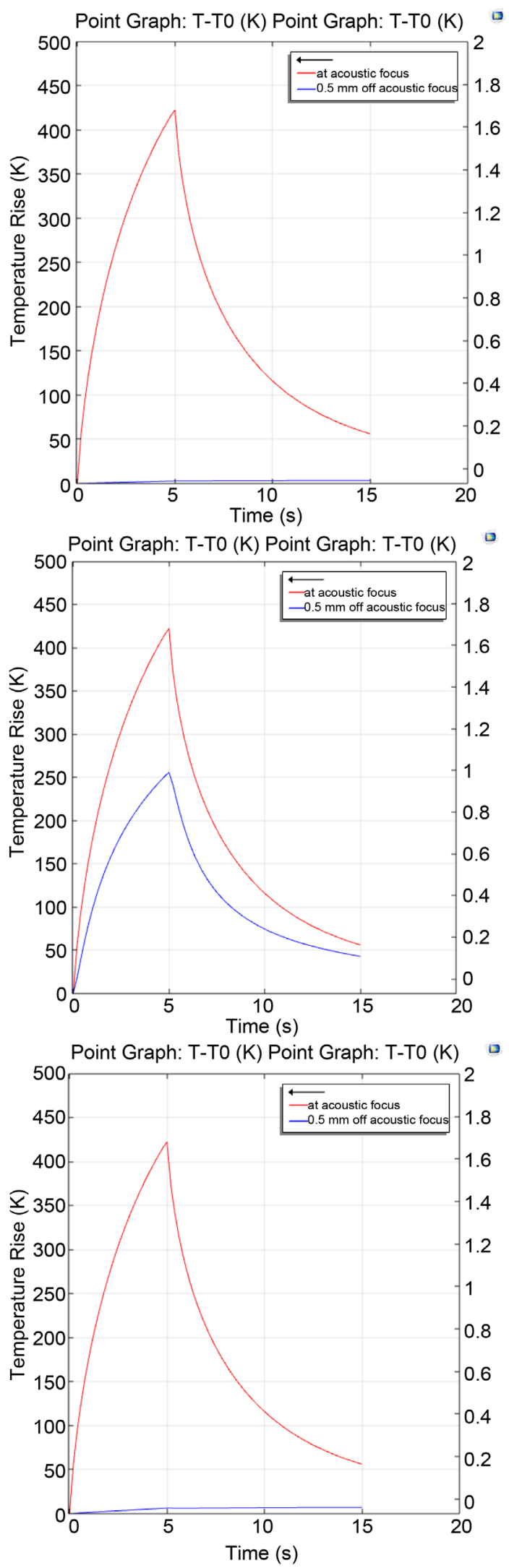

Figure 15. Temperature profile near fat at $50 \mathrm{~mm}, 57$ $\mathrm{mm}, 70 \mathrm{~mm} p_{0}=10 \mathrm{MPa} \cdot \mathrm{s}$ at $3 \mathrm{MHz}$. 

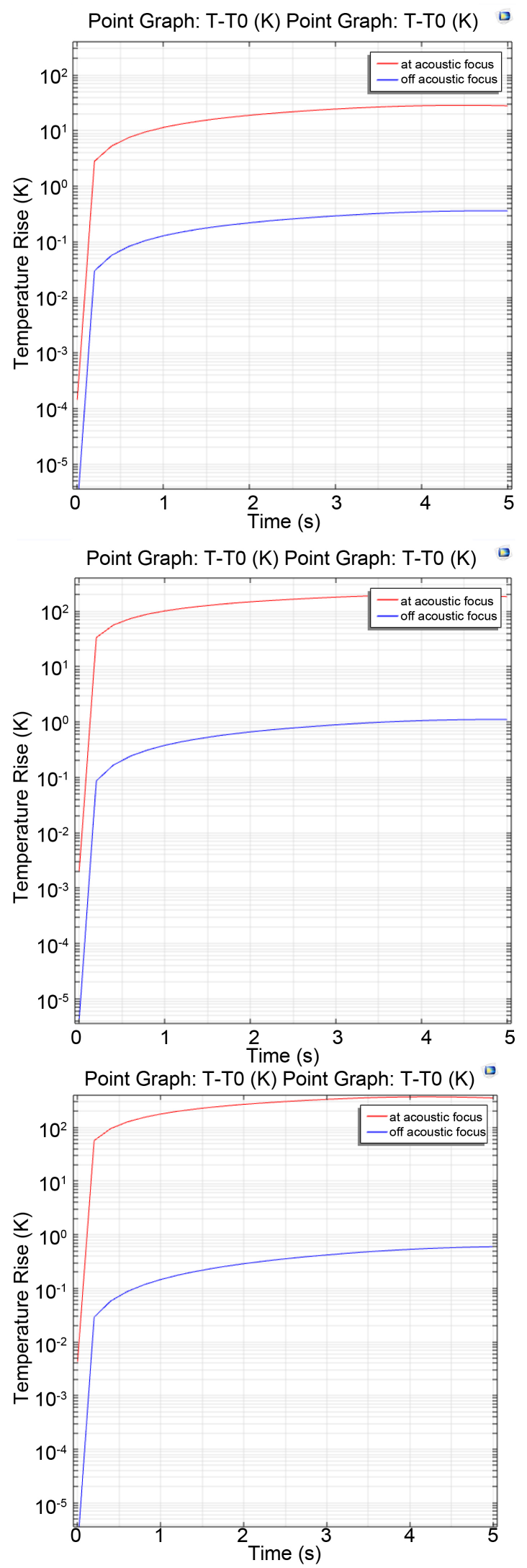

Figure 16. Temperature profile for bones at $p_{0}=10$ $\mathrm{MPa} \cdot \mathrm{s}$ for $1 \mathrm{MHz}, 2 \mathrm{MHz}$ and $3 \mathrm{MHz}$. 
(NEMS) [9] [10].

The approach followed here may be limited to the energy absorbed by the body so the temperature change should not exceed the upper limit for the human tissue. Therefore, the time frame for the energy source application should be limited to the maximum energy allowed for the human tissue. A 0.6 SAR (specific absorption rate) usually considered for human tissue [11]. The research parameters should be appropriate for the future practical model using MEMS (Micro Electro Mechanical Systems) and NEMS (Nano Electro Mechanical Systems) devices.

\section{References}

[1] Keene, D., et al. (2014) Effect on Cardiovascular Risk of High Density Lipoprotein Target Drug Treatments Niacin, Fibrates, and CETP Inhibitors: Meta-Analysis of Randomised Controlled Trials Including 117411 Patients. BMJ, 349, g4379. https://doi.org/10.1136/bmj.g4379

[2] Oraevsky, A.A. and Karabutov, A.A. (2000) Ultimate Sensitivity of Time-Resolved Optoacoustic Detection. SPIE Proceedings, 3916. https://doi.org/10.1117/12.386326

[3] Zeng, Y., et al. (2004) Photoacoustic and Ultrasonic Coimage with a Linear Transducer Array. Optics Letters, 29, 1760-1762. https://doi.org/10.1364/OL.29.001760

[4] Oraevsky, A.A., et al. (2002) Optoacoustic Imaging of Blood for Visualization and Diagnostics of Breast Cancer. SPIE Proceedings, 4618. https://doi.org/10.1117/12.469851

[5] Li, P.-C., et al. (2008) In Vivo Photoacoustic Molecular Imaging with Simultaneous Multiple Selective Targeting Using Antibody-Conjugated Gold Nanorods. Optics Express, 16, 18605-18615. https://doi.org/10.1364/OE.16.018605

[6] Wang, B., et al. (2010) Detection of Lipid in Atherosclerotic Vessels Using Ultrasound-Guided Spectroscopic Intravascular Photoacoustic Imaging. Optics Express, 18, 4889-4897. https://doi.org/10.1364/OE.18.004889

[7] Flores, R., Sui, Y., Yeung, J., et al. (2008) Multi-Sectioned Circular Surface Acoustic Wave Resonator Biosensor for Cancer Detection.

[8] Thella, A.K., et al. (2017) Dynamic Thermal/Acoustic Response for Human Bone Materials at Different Energy Levels: A Diagnosis Approach. Journal of Orthopaedics, 14, 85-90.

[9] Mahmood, A., et al. (2003) Micromachined Infrared Sensor Arrays on Flexible Polyimide Substrates. Sensors, 22-24 October 2003, Vol. 2, 777-782.

[10] Shamanna, V., et al. (2006) Micromachined Integrated Pressure-Thermal Sensors on Flexible Substrates. Journal of Micromechanics and Microengineering, 16, 1984.

[11] Perez, F., et al. (2016) Electromagnetic and Thermal Simulations of Human Neurons for SAR Applications. Journal of Biomedical Science and Engineering, 9, 437. 
Submit or recommend next manuscript to SCIRP and we will provide best service for you:

Accepting pre-submission inquiries through Email, Facebook, LinkedIn, Twitter, etc. A wide selection of journals (inclusive of 9 subjects, more than 200 journals)

Providing 24-hour high-quality service

User-friendly online submission system

Fair and swift peer-review system

Efficient typesetting and proofreading procedure

Display of the result of downloads and visits, as well as the number of cited articles Maximum dissemination of your research work

Submit your manuscript at: http://papersubmission.scirp.org/

Or contact wicd@scirp.org 